\title{
BMJ Open Early weight gain after stopping smoking: a predictor of overall large weight gain? A single-site retrospective cohort study
}

\author{
Alexandra Pankova, ${ }^{1,2}$ Eva Kralikova, ${ }^{1,2}$ Kamila Zvolska, ${ }^{1,2}$ Lenka Stepankova, ${ }^{1,2}$ \\ Milan Blaha, ${ }^{3}$ Petra Ovesna, ${ }^{3}$ Paul Aveyard ${ }^{4}$
}

To cite: Pankova A, Kralikova E, Zvolska K, et al. Early weight gain after stopping smoking: a predictor of overall large weight gain? A single-site retrospective cohort study. BMJ Open 2018;8:e023987. doi:10.1136/ bmjopen-2018-023987

- Prepublication history for this paper is available online. To view these files, please visit the journal online (http://dx.doi. org/10.1136/bmjopen-2018023987).

Received 16 May 2018 Revised 12 November 2018 Accepted 14 November 2018

Check for updates

(c) Author(s) (or their employer(s)) 2018. Re-use permitted under CC BY-NC. No commercial re-use. See rights and permissions. Published by BMJ.

For numbered affiliations see end of article.

Correspondence to Dr Alexandra Pankova; alexandra.pankova@lf1.cuni.cz

\section{ABSTRACT}

Objectives Most people gain weight on stopping smoking but the extent of weight gain varies greatly. Interventions aimed at all quitters to prevent weight gain on cessation have proven unpopular but targeting people who have gained excess weight immediately after quitting may improve uptake and cost-effectiveness. We examined whether early large postcessation weight gain predicts overall large weight gain.

Design Retrospective cohort study.

Setting Primary care setting-smoking cessation centre in Prague, Czech Republic.

Participants Out of 3537 patients treated between 2005 and 2013, 1050 were continuous abstainers (verified by carbon monoxide measurement) at 1-year follow-up and formed the cohort of the current report. $48.7 \%$ were women $(n=511)$ with the mean age of $46( \pm 14.4)$ years. Methods In this retrospective cohort study, all patients underwent usual tobacco dependence treatment using evidence-based methods. Weight was measured prior to smoking cessation and at each visit after quitting. Results The mean weight gain in the first month $(n=763)$ was $0.79 \%( \pm 2.03 \%)$, in the second month $(n=646)$ was $1.49 \%( \pm 2.58 \%)$, for the third month $(n=566) 2.33 \%$ $( \pm 3.44 \%)$ and $4.1 \%( \pm 5.31 \%)$ after 1 -year follow-up $(n=1050)$. The regression coefficient per $1 \%$ rise in the first 3 months was $+0.13 \%(95 \% \mathrm{Cl}-0.04 \%$ to $0.30 \%)$. A receiver operating curve analysis showed that patients gaining more than $0.98 \%$ of their baseline weight during first 3 months had a sensitivity of $66 \%$ and specificity of $44 \%$ for gaining $7 \%$ or more weight by 12 months. In addition, lower body mass index and an increase in appetite at 3 months after quitting were associated with greater weight gain, while using nicotine replacement therapy was associated with less weight gain at 1-year follow-up.

Conclusions People who stop smoking and gain a larger amount of weight early after quitting are not more likely to gain excessively at 1 year.

\section{INTRODUCTION}

Postcessation weight gain (PCWG) is a well-known phenomenon ${ }^{1-4}$ which occurs in majority of quitters ${ }^{56}$ and the average
Strengths and limitations of this study

- Our study contains one of the largest cohorts of abstinent smokers followed up for 12 months and thus allows more precise estimates of weight gain than most similar studies.

- Moreover, the cohort was well phenotyped at baseline and had serial weight measurements, which allowed us to characterise the trajectory of weight gain.

- The main limitation of our study is that it was based on the data from a routine clinic and not designed to assess the true determinants of weight change (eg, caloric intake, physical activity, resting metabolic rate), and thus we lack data on the true causal factors underlying weight gain.

weight gain is nearly $5 \mathrm{~kg}$ at 1 year postquit. ${ }^{37}$ However, weight change after cessation varies greatly, with around $16 \%$ losing weight while $13 \%$ gain more than $10 \mathrm{~kg}$ and it is currently unclear what predicts excess weight gain. ${ }^{3}$ The rate of weight gain is highest in the first 3 months after quitting. ${ }^{3}$

The exact mechanisms underlying weight gain are not clearly understood. It has been suggested that the occurrence of PCWG in most quitters is a result of imbalance in which energy input (eg, caloric intake) is in disequilibrium with energy expended (eg, physical activity, resting metabolic rate). ${ }^{1}$ On the other hand, it remains unclear why this imbalance occurs. One possible explanation is nicotine withdrawal. ${ }^{8}$ Although nicotine does not have an anorectic function and does not acutely reduce hunger and eating, ${ }^{9}$ it reduces food consumption and increases basal metabolic rate. ${ }^{89}$ In animal models, a decreased appetite was caused by binding of nicotine to the $\beta 4$ subunit of nicotinic acetylcholine receptors in the hypothalamus, which stimulates the melanocortin-4 (MC-4) 
Table 1 Baseline characteristics $(n=1050)^{*}$

\begin{tabular}{|c|c|c|}
\hline Personal characteristics & $\mathbf{N}(\%) \dagger$ & $\begin{array}{l}\text { Mean }( \pm S D) \ddagger \\
\text { Median (25th; } \\
\text { 75th) } \ddagger\end{array}$ \\
\hline $\begin{array}{l}\text { Patients stopped smoking } \\
\text { with 1-year follow-up } \\
(n=3043)\end{array}$ & $1050(34.5)$ & \\
\hline \multicolumn{3}{|l|}{ Gender $(n=1050)$} \\
\hline Female & $511(48.7)$ & \\
\hline Male & $539(51.3)$ & \\
\hline $\begin{array}{l}\text { Age at baseline visit (years) } \\
(n=1050)\end{array}$ & & $\begin{array}{l}46.2( \pm 14.4) \\
45.0(33.0 ; 58.0)\end{array}$ \\
\hline$\leq 39$ & $421(40.1)$ & \\
\hline $40-49$ & $173(16.5)$ & \\
\hline $50-59$ & $223(21.2)$ & \\
\hline$\geq 60$ & $233(22.2)$ & \\
\hline Weight (kg) $(n=1050)$ & & $\begin{array}{l}80.0( \pm 16.8) \\
78.6(67.1 ; 91.8)\end{array}$ \\
\hline$<60$ & $110(10.5)$ & \\
\hline $60-79$ & $446(42.5)$ & \\
\hline 80-99 & $358(34.1)$ & \\
\hline $100-119$ & $122(11.6)$ & \\
\hline$\geq 120$ & $14(1.3)$ & \\
\hline BMI $\left(k g / m^{2}\right)(n=1048)$ & & $\begin{array}{l}26.4( \pm 9.3) \\
25.7(22.9 ; 28.8)\end{array}$ \\
\hline$<20$ & $59(5.6)$ & \\
\hline $20-25$ & $392(37.4)$ & \\
\hline $25-30$ & $400(38.2)$ & \\
\hline$\geq 30$ & $197(18.8)$ & \\
\hline BDI score $(n=890) \S$ & & $\begin{array}{l}8.7( \pm 7.7) \\
7.0(3.0 ; 12.0)\end{array}$ \\
\hline Minimal depression & $272(33.5)$ & \\
\hline Mild depression & $427(52.5)$ & \\
\hline Moderate depression & $94(11.6)$ & \\
\hline Severe depression & $20(2.5)$ & \\
\hline FTCD $(n=1046)$ & & $\begin{array}{l}5.5( \pm 2.3) \\
6.0(4.0 ; 7.0)\end{array}$ \\
\hline $0-5$ & $527(50.4)$ & \\
\hline$\geq 6$ & $519(49.6)$ & \\
\hline Cigarettes per day $(n=1045)$ & & $\begin{array}{l}22( \pm 9.6) \\
20(20 ; 25)\end{array}$ \\
\hline $1-10$ & $98(9.4)$ & \\
\hline $11-20$ & $585(56.0)$ & \\
\hline $21-30$ & $243(23.3)$ & \\
\hline$\geq 31$ & $119(11.4)$ & \\
\hline $\begin{array}{l}\text { Regular smoking initiation } \\
\text { age }(n=1046)\end{array}$ & & $\begin{array}{l}19( \pm 4.9) \\
18.0(16 ; 20)\end{array}$ \\
\hline$\leq 18$ & $604(57.7)$ & \\
\hline$\geq 19$ & $442(42.3)$ & \\
\hline Physical activity $(n=1050)$ & & \\
\hline
\end{tabular}

Continued
Table 1 Continued

\begin{tabular}{|c|c|c|}
\hline Personal characteristics & $\mathbf{N}(\%) \dagger$ & 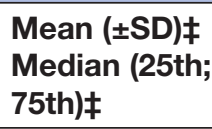 \\
\hline $\begin{array}{l}\text { Regularly (more times } \\
\text { weekly) }\end{array}$ & $264(25.1)$ & \\
\hline Weekly & $189(18.0)$ & \\
\hline Irregularly & $206(19.6)$ & \\
\hline Never & 391 (37.2) & \\
\hline
\end{tabular}

Pharmacotherapy used $\emptyset$

$(n=1050)$

\begin{tabular}{lc} 
Bupropion & $89(8.5)$ \\
Varenicline & $672(64.0)$ \\
$\begin{array}{l}\text { Nicotine replacement } \\
\text { therapy }\end{array}$ & $598(57.0)$ \\
Without therapy & $66(6.3)$ \\
\hline
\end{tabular}

*BDI; FTCD.

†Discrete variables are described by number and percentage.

$\ddagger$ Continuous variables are described by mean $( \pm S D)$ and median with 25-75 percentiles.

$\S B D I$ is only available for patients entered in 2007 and thereafter. It was not administered to patients early in the programme (2005-2006).

ПEach patient could have more than one pharmacotherapy. BDI, Beck Depression Inventory; FTCD, Fagerström Test of Cigarette Dependence.

subunit of pro-opiomelanocortin neurons. ${ }^{10}$ Increased appetite after smoking cessation is a frequent and longlasting withdrawal symptom ${ }^{11}$ and increased self-administration of palatable foods (ie, fatty meals and sweets) has been described after nicotine deprivation. ${ }^{12}$ Furthermore, smokers display an altered brain response to food in the hypothalamus, which is an area associated with long-term weight change in non-smokers. ${ }^{13}$ Additionally, delayed gastric emptying of solids has been explored in smokers ${ }^{14}$ and recent data described accelerated gastric motility after stopping smoking, and this may be involved in the temporary appetite increase. ${ }^{16}$ The role of gut microbiota modulation after smoking cessation has been introduced recently: profound shifts in the microbial composition and diversity were observed, and these changes seem to be similar to those already reported in obese compared with lean people, suggesting a potential pathogenetic link between weight gain and smoking cessation. ${ }^{17}$ Finally, the role of hereditary factors in weight changes after smoking cessation was suggested in a study with monozygotic and dizygotic twin quitters. ${ }^{18} 19$

PCWG is important. Fear of weight gain may be an important barrier for quitting smoking ${ }^{20}$ or may lead to loss of motivation and to relapse. ${ }^{21}$ In addition, weight gain has adverse consequences increasing cardiometabolic risk. $^{3}$

It would be helpful to identify those at high risk of excessive weight gain and intervene before they gain 
Table 2 Early weight gain/loss in the first 3 months after smoking cessation

\begin{tabular}{|c|c|c|c|c|c|c|}
\hline & $\mathbf{N}$ & Mean & SD & Median & Minimum & Maximum \\
\hline Baseline weight (kg) & 1050 & 80.0 & 16.78 & 78.6 & 44.3 & 136.0 \\
\hline \multicolumn{7}{|l|}{ Change $(\mathrm{kg})$ in early weight gain in } \\
\hline Second month & 646 & 1.12 & 2.04 & 1.10 & -7.60 & 8.00 \\
\hline Third month & 566 & 1.81 & 2.72 & 1.80 & -11.00 & 13.30 \\
\hline \multicolumn{7}{|l|}{ Relative change (\%) in early weight gain in } \\
\hline First month & 763 & 0.79 & 2.03 & 0.70 & -8.2 & 19.2 \\
\hline Second month & 646 & 1.49 & 2.58 & 1.49 & -10.1 & 10.0 \\
\hline Third month & 566 & 2.33 & 3.44 & 2.20 & -12.7 & 26.7 \\
\hline Median PCWG during first 3 months & 933 & 1.37 & 2.33 & 1.28 & -10.1 & 12.8 \\
\hline
\end{tabular}

PCWG, postcessation weight gain.

excessively. Risk factors for those at higher risk of PCWG have been intensively studied and identified (eg, higher baseline smoking rate, more severe cigarette dependence, less physical activity and a report of increased appetite on the baseline assessment of withdrawal symptoms, ${ }^{4}$ baseline weight (smokers who are obese gain most weight on quitting smoking) ${ }^{22}$ ) and others. However, these risk factors only poorly predict $\mathrm{PCWG}^{22}$ and thus cannot be used to identify high-risk smokers before they stop smoking that may benefit from interventions to prevent excessive weight gain. One plausible risk factor is early rapid weight gain; if a person has manifested weight gain already, this may well be the most important risk factor, but there are no data on whether this is the case. It is also plausible that a person who has gained weight rapidly may be motivated to address their weight. Finally, it may be easier for people to engage in weight control once they have passed the initial period of tobacco withdrawal. The main research question of this analysis is whether early large PCWG (ie, the weight gain within 3 months

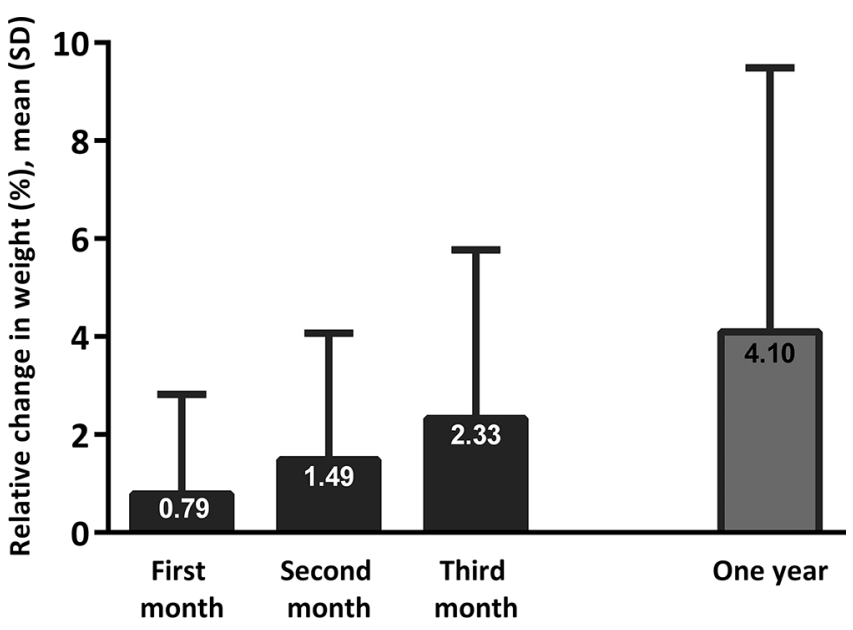

Time after quit smoking

Figure 1 Relative change in weight (\%) in different time points after smoking cessation (mean, SD). after quitting smoking) predicts overall large PCWG (ie, the total weight gain after 12 months since the quit date). Additionally, we examined other predictors of long-term PCWG and performed the receiver operating characteristic (ROC) analysis to find a cut point in the amount of early PCWG beyond which greater longer-term PCWG is likely to occur.

\section{MATERIALS AND METHODS}

\section{Tobacco dependence treatment programme}

This study population comprises patients treated at the Centre for Tobacco-Dependence in Prague, Czech Republic, between 2005 and 2013. This centre used evidence-based tobacco treatment procedures including pharmacotherapy and psychobehavioural interventions according to Czech and international treatment recommendations and guidelines, ${ }^{23}{ }^{24}$ described on our webpage at http://www.slzt.cz/intervention-structure. The multidisciplinary treatment team consisted of nurses and medical doctors who were certified as tobacco treatment specialists by the Mayo Clinic Accredited Tobacco Treatment Specialist Programme (accredited by the Council on Tobacco Treatment Training Programmes), and its equivalent in the Czech Republic under the Society for Treatment of Tobacco Dependence (accredited by the Czech Medical Association). The treatment is individualised and differs in the type of medication used (varenicline; bupropion; nicotine replacement therapy (NRT); the method of NRT including the patch, lozenge, inhaler and gum and/or in combination, if needed), and the number of clinic visits recommended depending on the history, preferences, adherence of patients and the presence of other comorbidities.

The initial visit, which included baseline assessments, was similar for all patients. The degree of tobacco dependence (Fagerström Test of Cigarette Dependence $(\text { FTCD })^{25} 26$ and Minnesota Withdrawal Scale (MNWS) ${ }^{27}$ ) were assessed, medical history was collected and a basic 
Table 3 Weight gain at 1-year follow-up in subgroups defined using median in the first 3 month periods after quit smoking

\begin{tabular}{lllllllll}
\hline & & \multicolumn{6}{l}{ Beyond weight gain (\%) up to 1 year follow-up } \\
\cline { 3 - 8 } Early weight change in & Group* & $\mathbf{N}$ & Mean & SD & Median & Minimum & Maximum & P values \\
\hline Three months (median) & $\leq 1.28 \%$ & 467 & 3.79 & 5.23 & 3.55 & -12.5 & 25.2 & \\
& $>1.28 \%$ & 466 & 4.13 & 5.55 & 3.81 & -13.6 & 26.6 & 0.384 \\
\hline
\end{tabular}

${ }^{*}$ According to median of early weight change (in \%).

physical examination was performed, which included height and weight.

At the second visit, physical dependence and psychosocial tobacco dependence were discussed during the 2-hour clinical intervention. Habits and rituals associated with tobacco use, alternative or surrogate means of resolving problems or avoiding such situations were analysed; and pharmacotherapy was introduced. At the end of the second visit, the patient and tobacco treatment specialist determined the subsequent course of treatment, including pharmacotherapy type and dose. They also planned the target quit date and the date of the first follow-up visit. Medication was prescribed based on the patient's history and choice. The first-line medications used in the clinical practice included varenicline, bupropion and/or nicotine. Whereas varenicline and bupropion were used in standard or reduced dosing, NRT was recommended either as the patch plus method (ie, patch in combination with an oral form of NRT-gum, mouth spray, oral strips, inhaler or lozenge) or in oral form only. Dosing of NRT was adjusted individually according to the presence of nicotine withdrawal symptoms during tobacco treatment. In accordance to Czech and international treatment recommendations and guidelines, ${ }^{2324}$ all drugs were recommended to be used for at least 3 months or longer if needed, according to withdrawal symptoms. The second visit also contained brief weight management recommendations, as described by Fiore and colleagues. ${ }^{23}$

Follow-up visits lasted an average of $30 \mathrm{~min}$. The first of these was planned within 1 or 2 weeks of the target quit day, and then about once a month through the third month of treatment. Regular in-person visits occurred at 6 and 12 months postquit date, with a higher frequency if needed. At each visit measurements of body weight, carbon monoxide $(\mathrm{CO})$ in expired air, blood pressure and heart rate were taken. Anyone that failed to attend a planned appointment was contacted by phone and classified as smoking if they did not attend as planned.

\section{Participants}

All participants signed a consent form to allow their data to be used in future studies such as this and this study was approved. The cohort consisted of 1050 smokers who underwent tobacco dependence treatment at the Centre for Tobacco-Dependence in Prague, Czech Republic, between 2005 and 2013. Out of 3537 patients treated during above-mentioned period, only 1050 fulfilled the inclusion criteria and were included in this analysis: 12 months of continuous abstinence (according to the Russell Standard Criteria ${ }^{28}$ ) verified by an exhaled $\mathrm{CO}$ of less than $6 \mathrm{ppm}$. Those who did not meet the above-mentioned inclusion criteria were excluded from this study.

\section{Patient and public involvement}

Patients were not involved in the research question development, setting of outcome measures, study design, recruitment and conduct of this study.

\section{Study measures}

- Weight: The body weight was measured at each visit using the personal digital scale ETA1775 90000, light clothes, shoes off.

- Body mass index (BMI): BMI is the ratio of body weight to the body surface calculated using the standard formula of $\mathrm{kg} / \mathrm{m} 2 .{ }^{29}$

- Beck Depression Inventory (BDI) score: Depressive symptoms were assessed at the baseline interview using the BDI. ${ }^{30}$ For analyses, patients were categorised into none or minimal (BDI $<13$ ), mild (BDI 14-19), moderate (BDI 20-28) and severe (BDI >28) depression.

- Tobacco dependence (FTCD): Tobacco dependence was measured using the FTCD ${ }^{25} 26$ at the baseline. An FTCD score of 5 or greater means severe dependence on tobacco.

- Number of cigarettes per day: Number of cigarettes smoked per day at the baseline visit (prior to any intervention).

- Regular smoking initiation age: Age when the smoker started to smoke regularly.

- Pharmacotherapy used: including bupropion, varenicline, NRT.

- Withdrawal symptoms: Withdrawal symptoms were assessed using the $\mathrm{MNWS}^{27}$ at each visit for last 24 hours (score $0-4$, where 4 means the most severe intensity and 0 means none). For this analysis, we used scores on one item related to noticing appetite and weight increases and the values recorded at baseline and at 3 months.

\section{Data analysis}

A special programme, ELZT (Evidence Léčby Závislosti na Tabáku-Register of Tobacco Dependence Treatment) was developed to collect and summarise data from the Centre for the Treatment of Tobacco Dependence, General University Hospital and 1 st Faculty of Medicine, Charles University. 
Table 4 ROC analyses of early weight gain for groups of patients defined using limits $5 \%, 7 \%, 10 \%$ wt gain in 1 year follow-up $(n=772)$

\begin{tabular}{|c|c|c|c|c|}
\hline \multicolumn{2}{|c|}{$\begin{array}{l}\text { Weight gain up to } \\
1 \text { year follow-up }\end{array}$} & \multicolumn{3}{|c|}{$\begin{array}{l}\text { Early weight gain (\%) ROC } \\
\text { analyses }\end{array}$} \\
\hline Limit (\%) & $\mathbf{n}_{>\text {limit }}$ & Cut-off (\%) & Sensitivity & Specificity \\
\hline $5 \%$ & $N_{>5 \%}=296$ & 2.28 & 0.395 & 0.716 \\
\hline \multirow[t]{2}{*}{$7 \%$} & $N_{>7 \%}=201$ & 2.35 & 0.426 & 0.725 \\
\hline & & 0.98 & 0.658 & 0.440 \\
\hline $10 \%$ & $N_{>10 \%}=93$ & 2.86 & 0.344 & 0.794 \\
\hline
\end{tabular}

ROC, receiver operating characteristic.

Data were analysed by the Institute of Biostatistics and Analyses at the Faculty of Medicine and the Faculty of Science Masaryk University, Brno. Baseline characteristics were summarised using mean $\pm \mathrm{SD}$ and median with quartiles for continuous variables and using absolute and relative frequencies for categorical variables. Body measurement changes from baseline to 1 year were calculated as absolute change and also as percentage change. A one-sample t-test assessed the significance of change in weight against zero (no change). The relation between relative changes in early weight gain and weight gain up to 1-year follow-up period were assessed by Pearson correlation. The aim was to set a threshold of early weight gain (ie, within 3 months of the quit date), which might indicate further weight gain. We assessed this in two different ways: (1) Change in early weight gain/loss was dichotomised at the median and mean weight change from that point forward to 1 year was compared by a two-sample t-test. (2) Then the ROC analyses were used to find cut-offs for definition of limits for risk subgroups. Cut-offs were chosen using the best combination of sensitivity (true-positive rate) and specificity (true-negative rate). We preferred higher sensitivity to specificity. This is because in any future use of the cut-offs will aim to maximise health gain by offering weight control interventions to anyone at high risk.

Analysis of variance and Pearson correlation were used to assess the association between 1-year weight gain and baseline characteristics. A multiple linear regression model followed univariate analyses; all factors were included in the model except for BDI score, which was missing in many patients and, moreover, BDI score was not statistically significantly associated in the univariate analysis. In addition, multiple imputation of missing data of all involved variables was applied; the fully conditional specification method based on an iterative Markov chain Monte Carlo method was chosen because the pattern of missing data was arbitrary (BMI was imputed in two patients; FTCD, number of cigarettes per day and age at smoking initiation were imputed in three patients and BDI was imputed in 162 patients). Full multivariable linear model including BDI score were created on the imputed data. Multivariable models were used to assess the association between early weight gain and subsequent weight gain controlling for other possible factors associated with weight gain (gender, age, BMI, BDI, FTCD, number of cigarettes, age at smoking initiation, physical activity and pharmacotherapy). In addition, we computed association between the withdrawal appetite score at 3 months and mean weight gain at 12 months. The sensitivity analysis with those present at both time points $(n=566)$ was performed in order to examine the predictive ability of early weight regain on later weight regain. All tests were done on a significance level $\alpha=0.05$, analyses were conducted using SAS V.9.4 and IBM SPSS Statistics V.23.

\section{RESULTS}

The baseline characteristics of our patients are shown in table 1 .

The sample of 1050 successful abstainers consisted of $511(48.7 \%)$ women and $539(51.3 \%)$ men with the mean age of $46( \pm 14.4)$ years. The mean PCWG after 1 year was $+4.1 \%( \pm 5.31 \%)$ of the baseline weight. When examined by month, it was $0.79 \%( \pm 2.03 \%)$ at first month, $1.49 \%$ $( \pm 2.58 \%)$ at second month and $2.33 \%( \pm 3.44 \%)$ at third month $(\mathrm{p}<0.001$ for all above-mentioned changes) (see table 2, figure 1 ).

Between the baseline visit and 3 months after smoking cessation, early weight gain/loss was significantly correlated with subsequent weight gain at 1 year $(\mathrm{p}=0.018$, correlation coefficient was +0.085 ), which indicated that early weight gain was only weakly related with subsequent weight gain.

If we dichotomised patients according to median of early weight change $(1.28 \%)$ into above and below the median, subsequent weight gain recorded in patients with early weight gain above median was not significantly higher compared with those under the median value (see table 3).

Findings from the receiver operating curve analysis are shown in table 4.

Early weight change during the first 3 months after stopping smoking did not strongly predict subsequent weight gain and it had a low sensitivity. Forty three per cent of patients $(n=453)$ gained more than $7 \%$ of their baseline weight by 12 months. A receiver operating curve analysis showed that patients gaining more than $0.98 \%$ of their baseline weight during the first 3 months had a sensitivity of $66 \%$ and specificity of $44 \%$ for gaining $7 \%$ or more weight beyond by 12 months. The waterfall plot in figure 2 shows that one-third of people who gained less than $0.98 \%$ during the first 3 months further gained more than $7 \%$ at 1 year, but more than half of those who gained more than $0.98 \%$ at this time did not gain more than $7 \%$.

There was no evidence that participants' appetite ratings at baseline, before quitting, was associated with weight gain at 12 months. However, there was a graded association between appetite ratings at 3 months and weight gain at 12 months (figure 3 ).

Multivariate linear regression on imputed data (see table 5) showed that significant factors for prediction 


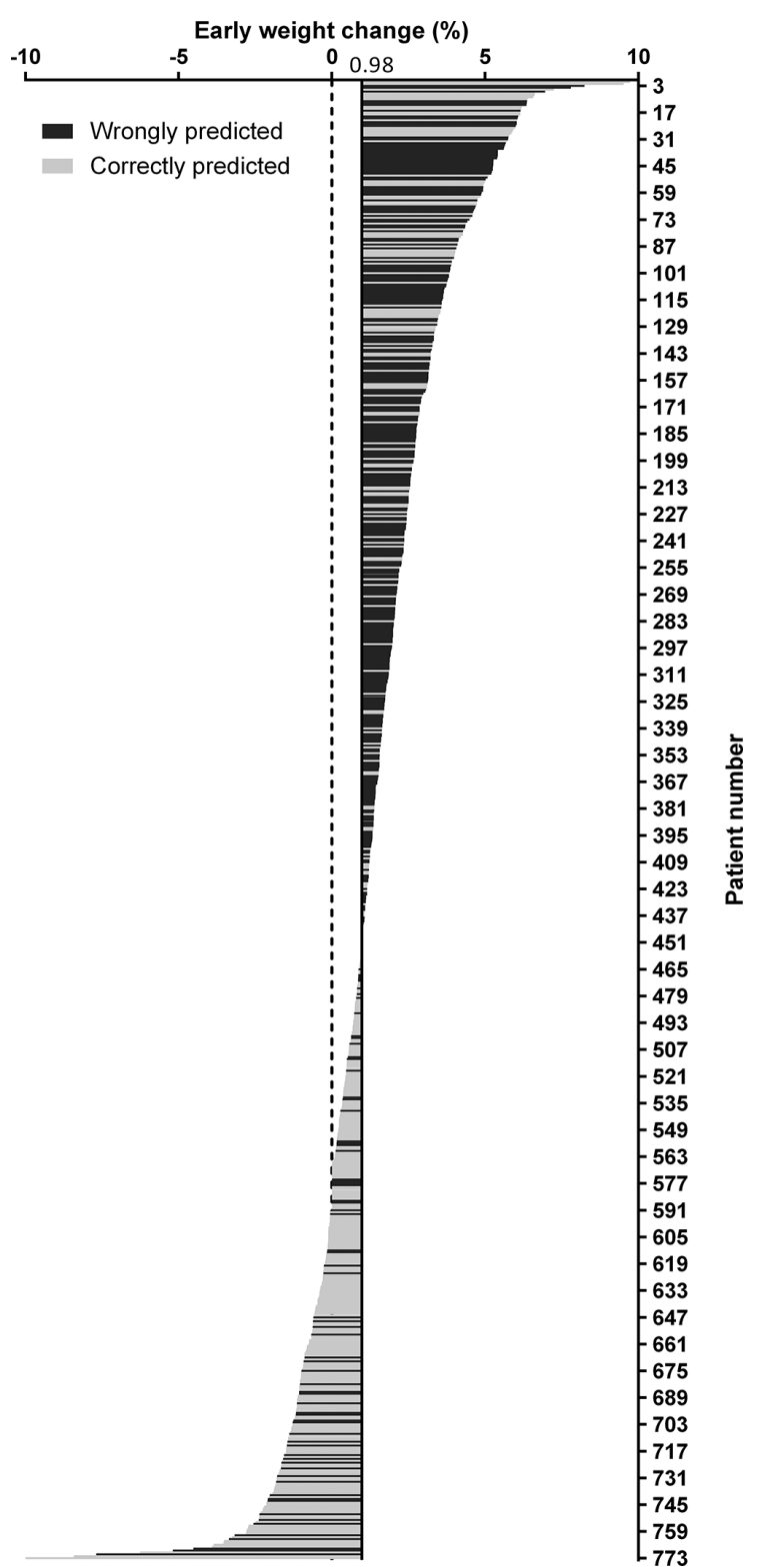

Figure 2 Waterfall plot for prediction of subsequent $>7 \%$ weight gain up to 1 year FU by early weight change (Each patient is represented by one horizontal line). Patients with $<0.98 \%$ weight gain at third month are on the left side; patients with $\geq 0.98 \%$ weight gain on the right side. Grey lines depict correctly predicted patients, that is, positive ( $\geq 0.98 \%$ early weight gain and $>7 \%$ subsequent weight gain up to 1 year; in upper part of plot) and negative $(<0.98 \%$ early weight gain and $\leq 7 \%$ subsequent weight gain, in lower part of plot). Black lines depict wrongly predicted patients, that is, false positive $(\geq 0.98 \%$ early weight gain but $\leq 7 \%$ subsequent weight gain) and false negative $(<0.98 \%$ early weight gain but $>7 \%$ subsequent weight gain).

of higher PCWG after 1 year were lower baseline BMI $(\mathrm{B}=-0.20 ; 95 \% \mathrm{CI}-0.29$ to $-0.11, \mathrm{p}<0.001)$, being a woman $(\mathrm{B}=0.78 ; 0.02$ to $1.54, \mathrm{p}=0.045)$, while using NRT was associated with lower weight gain $(\mathrm{B}=-1.07 ;-1.88$ to $-0.26, \mathrm{p}=0.01$ ). The mean duration of use of oral forms of NRT was 4.43 months (median 2.88 months) and of nicotine patches 2.72 months (median 2.2 months). The

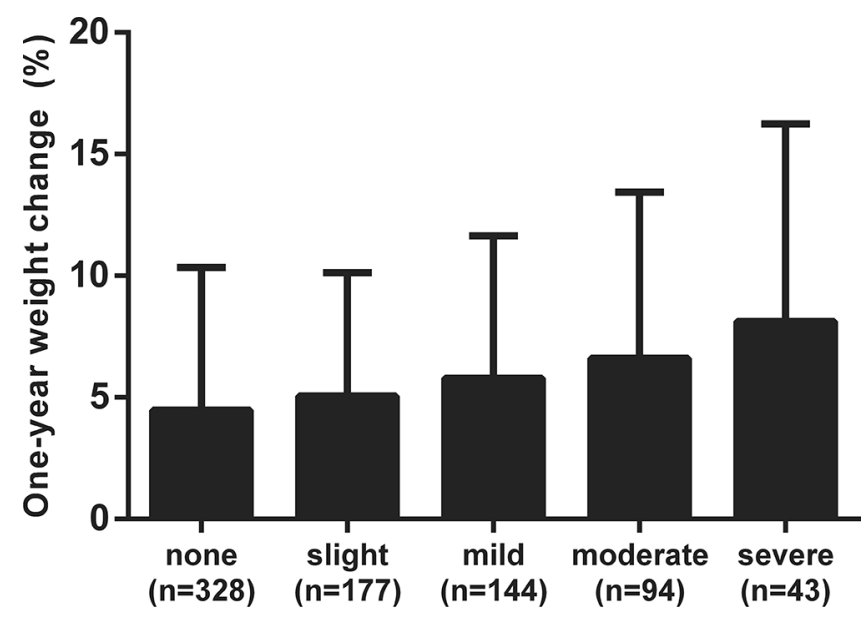

\section{Increased appetite, hungry, weight gain} at $3 \mathrm{~m}$ visit

Figure 3 Average weight gain after 1 year based on patients' reported intensity of withdrawal symptom 'increased appetite, hungry, weight gain' at 3-month visit; whiskers denote $95 \% \mathrm{Cl}$.

length of pharmacotherapy use was similar for all firstline medications (ie, varenicline, bupropion and NRT).

The sensitivity analysis performed with those present at both time points $(n=566)$ found the same factors significant in the main multivariate analysis as those from the whole sample of abstainers who missed any visit.

Early weight gain was not associated with additional weight gain thereafter when assessed at 1 year $(\mathrm{B}=0.14$, $95 \%$ CI $-0.03-0.31, \mathrm{p}=0.101)$.

\section{DISCUSSION}

There was not a statistically significant relationship between early weight gain and later weight gain. As a result, early weight gain above the median had a moderate sensitivity (66\%) and somewhat low specificity (44\%) for gaining at least $7 \%$ of baseline weight by 12 months. In multivariable analysis, having a lower BMI at baseline, starting smoking in adulthood and using either no medication or medication other than NRT were independently associated with greater weight gain at 1 year. In addition, postcessation appetite ratings were associated with greater weight gain. The relationship between early and later weight gain seems to be positive, but the discrepant findings from different analyses indicate that their relationship is weak.

We found that higher appetite ratings at 3 months were associated with greater weight gain at a year, but there was no association between appetite ratings at baseline, prior to quitting, and PCWG. This latter finding contrasts with those of Kmetova et $a l^{4}{ }^{4}$ where ratings of appetite prior to a quit attempt were associated with PCWG. To our knowledge, our finding that withdrawal symptoms of appetite intensity after smoking cessation have been associated with weight gain is in line with previously published studies. ${ }^{31} 32$ That 3 months appetite 
Table 5 Multiple linear model for relative change in weight 1 year after smoking cessation

\begin{tabular}{|c|c|c|c|c|}
\hline \multirow[b]{2}{*}{ Personal characteristics } & \multicolumn{2}{|l|}{ Multiple model $(n=765)$} & \multicolumn{2}{|c|}{ Model with multiple imputation ( $n=772)$} \\
\hline & Beta $(95 \% \mathrm{Cl})$ & $P$ values & Beta $(95 \% \mathrm{Cl})$ & $P$ values \\
\hline Weight change in third month (\%) & $0.134(-0.037$ to 0.304$)$ & 0.124 & 0.141 (-0.027 to 0.31$)$ & 0.101 \\
\hline Female & 0.804 (0.039 to 1.57$)$ & 0.039 & 0.781 (0.018 to 1.544$)$ & 0.045 \\
\hline Age at baseline visit (years) & $-0.005(-0.034$ to 0.024$)$ & 0.736 & $-0.006(-0.034$ to 0.023$)$ & 0.682 \\
\hline $\operatorname{BMI}\left(\mathrm{kg} / \mathrm{m}^{2}\right)$ & $-0.209(-0.3$ to -0.118$)$ & 0.000 & $-0.202(-0.292$ to -0.111$)$ & $<0.001$ \\
\hline BDI score & & & $0.021(-0.037$ to 0.078$)$ & 0.467 \\
\hline FTCD score & $0.004(-0.211$ to 0.218$)$ & 0.974 & $0(-0.214$ to 0.214$)$ & 1.000 \\
\hline Cigarettes per day & $0.033(-0.018$ to 0.084$)$ & 0.207 & $0.03(-0.021$ to 0.081$)$ & 0.243 \\
\hline Age at regular smoking initiation (years) & $0.05(-0.046$ to 0.145$)$ & 0.307 & $0.045(-0.05$ to 0.14$)$ & 0.356 \\
\hline Bupropion* & $0.011(-1.337$ to 1.359$)$ & 0.987 & $-0.049(-1.406$ to 1.309$)$ & 0.944 \\
\hline Varenicline* $^{*}$ & $-0.384(-1.267$ to 0.5$)$ & 0.395 & $-0.349(-1.225$ to 0.527$)$ & 0.435 \\
\hline Nicotine replacement therapy* & & 0.010 & $-1.068(-1.879$ to -0.257$)$ & 0.010 \\
\hline \multicolumn{5}{|l|}{ Physical activity } \\
\hline Regularly (more times weekly) & $-1.015(-2.072$ to 0.042$)$ & 0.060 & $-0.957(-2.01$ to 0.095$)$ & 0.075 \\
\hline Weekly & $-0.137(-1.185$ to 0.911$)$ & 0.798 & $-0.1(-1.146$ to 0.946$)$ & 0.851 \\
\hline Irregularly & $0.402(-0.657$ to 1.462$)$ & 0.457 & $0.466(-0.586$ to 1.519$)$ & 0.385 \\
\hline Never & ref. & & ref. & \\
\hline Intercept & 8.411 (4.993 to 11.828$)$ & $<0.001$ & 8.208 (4.795 to 11.621$)$ & $<0.001$ \\
\hline
\end{tabular}

*Using of specified pharmacotherapy (in monotherapy or in combination with other therapy).

BDI, Beck Depression Inventory; BMI, body mass index; FTCD, Fagerström Test of Cigarette Dependence.

ratings were a predictor suggests that this effect is longlived, which consonant with continued weight gain over continued smoking observed in populations is observed even beyond the first year. ${ }^{22}$

This study has several strengths. It is one of the largest cohorts of abstinent smokers followed up and thus allows more precise estimates of weight gain than most similar studies. Moreover, the cohort was well phenotyped at baseline and had serial weight measurements, which allowed us to characterise the trajectory of weight gain, which has previously been possible only in repeat cross-sectional samples. ${ }^{3}$ Perhaps, participants who were gaining weight rapidly noticed this and took actions to limit weight gain, which may explain why there was only a weak association between early and later weight gain. The most likely variables to be associated with greater or lower weight gain are likely to be the actions participants take to limit weight gain by limiting energy intake and maximising expenditure and the strength of drive to eat that participants experience after quitting smoking. There was evidence that the strength of drive to eat may explain greater weight gain, where postcessation ratings were associated with higher weight gain.

On the other hand, there are some limitations of our work. This study was based on the data from a routine clinic and not designed to assess the true determinants of weight change, which must relate to change in energy balance, and which are burdensome for participants to measure properly, and thus we lack data on the true causal factors underlying weight gain. No studies, to our knowledge, have ever tracked these factors through the first year of abstinence. This limitation particularly affects the study of factors associated with greater weight gain, which must be confined to indirect but easy to measure factors.

The extent of weight gain in this cohort was similar to that observed in previous studies and documented in a meta-analysis of such studies. ${ }^{3}$ However, as in the meta-analysis of previous studies, we found a large variation between individuals in the extent of weight gain. This implies that the mean weight gain is a poor predictor of what any individual might gain, so we need to identify better predictors if we are to offer targeted interventions to prevent excess weight gain. Unfortunately, even early manifest weight gain is a poor predictor of excess weight gain and our other predictors also accounted for only a matter of hundreds of grams difference between those with and without a particular risk factor, whereas there was a $5 \mathrm{~kg}$ difference in weight between a person in the 25th and 75th centile of the weight gain distribution. Nevertheless, there were some more potent predictors. Chief among these were BMI at baseline. The higher the BMI, the lower the weight gain. Other studies have reported both positive and negative associations with BMI and, overall, it seems that baseline BMI may not be a strong predictor of weight gain. ${ }^{22}$ Starting smoking later in life emerged as an unexpected predictor of higher weight gain, but a previous study has suggested that those who initiate smoking earlier may have higher weight gain. ${ }^{22}$ Third, using NRT was 
associated with lower weight gain. A meta-analysis of randomised trials suggests that, of all the licensed medications, bupropion may have the largest effect on weight gain, ${ }^{34}$ so this result may appear unexpected. However, people do not use varenicline or bupropion for more than a few months when stopping smoking, and there is no strong evidence that bupropion reduces weight gain in the long-term. ${ }^{34}$ Instead, the most likely explanation is that a sizeable proportion of people who seek treatment for tobacco dependence and who quit with NRT use it for at least a year and this is associated with and probably causes lower weight gain. ${ }^{35}$

These data have important implications for the treatment of tobacco dependence. We have conducted trials of interventions to limit weight gain where the interventions to do so have started concurrently with the attempt to achieve abstinence. ${ }^{36}{ }^{37}$ These interventions have been proven unpopular with people trying to stop smoking and the trials have failed to recruit. A promising avenue that may increase participants' desire to address weight gain may have been to wait until excess weight gain had been manifest and then intervene with a weight control programme. However, this study shows that, while early excessive weight gain does predict subsequent higher weight gain, it does so only weakly; many people who will not gain excessively would need to be treated and some people who will gain excessive weight will not be offered treatment. It may therefore be necessary to find ways to reframe the offer of weight control so that it is more attractive to people attempting to stop smoking, which may be helped if we can identify those at the greatest risk of health-damaging weight gain.

\section{CONCLUSIONS}

In conclusion, in people who stopped smoking for a year, excess weight gain in the first few months of abstinence is a poor predictor of later and excessive gain and there appear to be no other strong predictors of excessive weight gain that are measured in a routine smoking cessation clinic.

\section{Author affiliations \\ ${ }^{1}$ Centre for Tobacco-Dependent, 3rd Medical Department, First Faculty of Medicine, Charles University and the General University Hospital, Charles University, Prague, Czech Republic \\ ${ }^{2}$ Institute of Hygiene and Epidemiology, First Faculty of Medicine, Charles University and the General University Hospital, Charles University, Prague, Czech Republic ${ }^{3}$ Institute of Biostatistics and Analyses, Faculty of Medicine, Masaryk University, Brno, Czech Republic \\ ${ }^{4}$ Nuffield Department of Primary Care Health Sciences, University of Oxford, Oxford, UK}

Contributors AP and PA designed the study and wrote the protocol. LS and KZ conducted literature searches and provided summaries of previous research studies. PO and MB conducted the statistical analysis. EK wrote the first draft of the manuscript and all authors contributed to and have approved the final manuscript.

Funding This work was supported by the Charles University' institutional support, project PROGRES Q25/LF1. PA is an NIHR senior investigator and is funded by NIHR Oxford Biomedical Research Centre and the CLAHRC.
Disclaimer The views expressed are not necessarily those of the NIHR, NHS, or Department of Health.

Competing interests AP, EK, LS and KZ received payments for clinical studies and educational activities from pharmaceutical companies producing smoking cessation medication.

Patient consent Obtained.

Ethics approval Ethics Committee of the General University Hospital in Prague.

Provenance and peer review Not commissioned; externally peer reviewed.

Data sharing statement No additional data available.

Open access This is an open access article distributed in accordance with the Creative Commons Attribution Non Commercial (CC BY-NC 4.0) license, which permits others to distribute, remix, adapt, build upon this work non-commercially, and license their derivative works on different terms, provided the original work is properly cited, appropriate credit is given, any changes made indicated, and the use is non-commercial. See: http://creativecommons.org/licenses/by-nc/4.0/.

\section{REFERENCES}

1. Perkins KA. Weight gain following smoking cessation. J Consult Clin Psychol 1993;61:768-77.

2. Pistelli F, Aquilini F, Carrozzi L. Weight gain after smoking cessation. Monaldi Arch Chest Dis 2009;71:81-7.

3. Aubin HJ, Farley A, Lycett $D$, et al. Weight gain in smokers after quitting cigarettes: meta-analysis. BMJ 2012;345:e4439.

4. Kmetova A, Kralikova E, Stepankova L, et al. Factors associated with weight changes in successful quitters participating in a smoking cessation program. Addict Behav 2014;39:239-45.

5. Cairella G, Ciaralli F, Longo P, et al. [Smoking cessation and weight gain]. Ann Ig 2007;19:73-81.

6. Klein LC, Corwin EJ, Ceballos RM. Leptin, hunger, and body weight: Influence of gender, tobacco smoking, and smoking abstinence. Addict Behav 2004;29:921-7.

7. Chatkin R, Chatkin JM. [Smoking and changes in body weight: can physiopathology and genetics explain this association?]. J Bras Pneumol 2007;33:712-9.

8. Henningfield JE, London ED, Pogun S. Handbook of experimental pharmacology 192. Nicotine psychopharmacology. Preface. Handb Exp Pharmacol 2009:v-viii.

9. Filozof C, Fernández Pinilla MC, Fernández-Cruz A. Smoking cessation and weight gain. Obes Rev 2004;5:95-103.

10. Mineur YS, Abizaid A, Rao Y, et al. Nicotine decreases food intake through activation of POMC neurons. Science 2011;332:1330-2.

11. Hughes JR. Effects of abstinence from tobacco: etiology, animal models, epidemiology, and significance: a subjective review. Nicotine Tob Res 2007;9:329-39.

12. Hughes JR, Gust SW, Skoog K, et al. Symptoms of tobacco withdrawal. A replication and extension. Arch Gen Psychiatry 1991;48:52-9.

13. Geha PY, Aschenbrenner K, Felsted J, et al. Altered hypothalamic response to food in smokers. Am J Clin Nutr 2013;97:15-22.

14. Gritz ER, Ippoliti A, Jarvik ME, et al. The effect of nicotine on the delay of gastric emptying. Aliment Pharmacol Ther 1988;2:173-8.

15. Miller G, Palmer KR, Smith B, et al. Smoking delays gastric emptying of solids. Gut 1989;30:50-3.

16. Kadota K, Takeshima F, Inoue K, et al. Effects of smoking cessation on gastric emptying in smokers. J Clin Gastroenterol 2010;44:e71-e75.

17. Biedermann L, Zeitz J, Mwinyi J, et al. Smoking cessation induces profound changes in the composition of the intestinal microbiota in humans. PLoS One 2013;8:e59260.

18. Aveyard $P$, Lycett $D$, Farley $A$. Managing smoking cessation-related weight gain. Pol Arch Med Wewn 2012;122:494-8.

19. Swan GE, Carmelli D. Characteristics associated with excessive weight gain after smoking cessation in men. Am J Public Health 1995;85:73-7.

20. Borrelli B, Mermelstein R. The role of weight concern and selfefficacy in smoking cessation and weight gain among smokers in a clinic-based cessation program. Addict Behav 1998;23:609-22.

21. Jeffery RW, Hennrikus DJ, Lando HA, et al. Reconciling conflicting findings regarding postcessation weight concerns and success in smoking cessation. Health Psychol 2000;19:242-6.

22. Lycett $\mathrm{D}$, Munafò $\mathrm{M}$, Johnstone $\mathrm{E}$, et al. Associations between weight change over 8 years and baseline body mass index in a cohort of continuing and quitting smokers. Addiction 2011;106:188-96.

23. Fiore MC, Jaen CR, Baker TB, et al. Treating tobacco use and dependence: 2008 update, clinical practice guideline. executive 
summary. 2008 http://www.rcjournal.com/contents/09.08/09.08. 1217.pdf (Accessed 26 November 2017).

24. Králíková E, Češka R, Pánková $A$, et al. [Tobacco dependence treatment guidelines]. Vnitr Lek 2015;61:1S4-15.

25. Heatherton TF, Kozlowski LT, Frecker RC, et al. The fagerström test for nicotine dependence: a revision of the fagerström tolerance questionnaire. Br J Addict 1991;86:1119-27.

26. Fagerström K. Determinants of tobacco use and renaming the FTND to the Fagerstrom Test for Cigarette Dependence. Nicotine Tob Res 2012;14:75-8.

27. Hughes JR, Hatsukami D. Signs and symptoms of tobacco withdrawal. Arch Gen Psychiatry 1986;43:289-94.

28. West R, Hajek P, Stead L, et al. Outcome criteria in smoking cessation trials: proposal for a common standard. Addiction 2005;100:299-303.

29. World Health Organization. Health Topics. Obesity. 2016 http://www. who.int/topics/obesity/en/ (Accessed 17 Apr 2017).

30. Beck AT, Steer RA, Ball R, et al. Comparison of beck depression inventories -IA and -II in psychiatric outpatients. J Pers Assess 1996;67:588-97.
31. Can G, Oztuna F, Topbaș M. Complaints related to smoking cessation. Tuberk Toraks 2007;55:364-9.

32. John U, Meyer C, Rumpf HJ, et al. Predictors of increased body mass index following cessation of smoking. Am J Addict 2006;15:192-7.

33. Bacha S, Skandagi W, Khemiri M, et al. Assessment of eating behavior after smoking cessation. Tunis Med 2016;94:406-11.

34. Farley AC, Hajek P, Lycett D, et al. Interventions for preventing weight gain after smoking cessation. Cochrane Database Syst Rev 2012;1:CD006219.

35. Hajek P, Jackson P, Belcher M. Long-term use of nicotine chewing gum. Occurrence, determinants, and effect on weight gain. JAMA 1988:260:1593-6.

36. Lycett D, Hajek P, Aveyard P. Trial Protocol: randomised controlled trial of the effects of very low calorie diet, modest dietary restriction, and sequential behavioural programme on hunger, urges to smoke, abstinence and weight gain in overweight smokers stopping smoking. Trials 2010;11:94.

37. Lycett D, Aveyard P, Farmer A, et al. Slimming World in Stop Smoking Services (SWISSS): study protocol for a randomized controlled trial. Trials 2013;14:182. 